\title{
Kinetic control on the distribution of secondary precipitates during $\mathrm{CO}_{2}$-basalt interactions
}

\author{
Helge Hellevang ${ }^{1,}$, Domenik Wolff-Boenisch ${ }^{2}$, and Mohammad Nooraiepour ${ }^{1}$ \\ ${ }^{1}$ Department of Geosciences, University of Oslo, Postboks 1047, Blindern, Oslo, Norway \\ ${ }^{2}$ School of Earth and Planetary Sciences, Curtin University, GPO Box U1987, Perth, 6845 WA, \\ Australia.
}

\begin{abstract}
A combined experimental and numerical study was undertaken to better understand the spatial distribution of secondary mineral growth along a basalt column. The work demonstrated that few and large crystals formed at random locations. This can only be explained in terms of an overall control by mineral nucleation. The main implication is that a new probabilistic approach must be developed in order to get the overall kinetics and the distribution of crystal growth in the numerical models right.
\end{abstract}

\section{Introduction}

Understanding volume changes caused by mineral dissolution-precipitation reactions is of key importance to predict fluid flow and element mobilization in soils, sediments and in fractured rock aquifers. Slow mineral dissolution-precipitation reactions happen naturally as the systems proceed towards lower free energy. A variety of human activities on the other hand perturbate natural systems leading to orders of magnitude faster reactions, and, in aquifers, corresponding fast changes in fluid flow properties and element mobilization.

One activity that has received large focus over the last decades is underground $\mathrm{CO}_{2}$ storage, used to mitigate climate changes caused by greenhouse gas emissions. $\mathrm{CO}_{2}$ storage perturbates the natural aquifer systems by introducing increased $\mathrm{CO}_{2}$ partial pressures and thereby increasing dissolved inorganic carbon (DIC) and reducing $\mathrm{pH}$. This in turn leads to dissolution of the primary mineral phases and the formation of stable secondary aluminosilicates and carbonates [1]. Potential volume (porosity) changes are controlled by the carbonatization potential, by the molar volume differences between primary and secondary phases, and by the 'openness' of the system, i.e. if $\mathrm{CO}_{2}$ is supplied infinitely or if a finite amount of $\mathrm{CO}_{2}$ is available to react. Porosity changes for siliciclastic rocks have been suggested to be minor [2], whereas open-system carbonatization of basalts can, in theory, completely obliterate the porosity [3]. Permeability changes are harder to predict. Mineral dissolution-precipitation is a spatial redistribution of mass, and permeability may change significantly even with only minor changes in porosity, e.g. [4]. To be able to predict not only changes in porosity, but also changes in the porosity-permeability relation, the factors controlling the spatial distribution of the secondary phases must be known.

\footnotetext{
*Corresponding author: helghe@geo.uio.no
} 
This work used a novel column glass reactor together with PHREEQC simulations to study carbonate growth on a basaltic glass substrate. The aim was to investigate to what extent equilibrium thermodynamics and classical nucleation and mineral growth rate theories can be used to predict the spatial distribution of secondary phases. Finally, the implications for pore scale modelling, or continuum scale reactive transport modelling with numerical codes such as PHREEQC, are discussed.

\section{Materials and methods}

\subsection{D column experiments}

\subsubsection{Column setup}

One column experiment was performed using a $40 \mathrm{~cm} 14 \mathrm{~mm}$ inner diameter glass tube. A steady flow of $\mathrm{CO}_{2}$-charged water of $20 \mathrm{~cm} /$ day was achieved with a dual-piston ISCO pump (Fig. 1). Sampling was executed at the column inlet at discrete times, and continuously at the column outlet. The experiments were carried out at $80^{\circ} \mathrm{C}$ and atmospheric $\mathrm{CO}_{2}$ pressure.

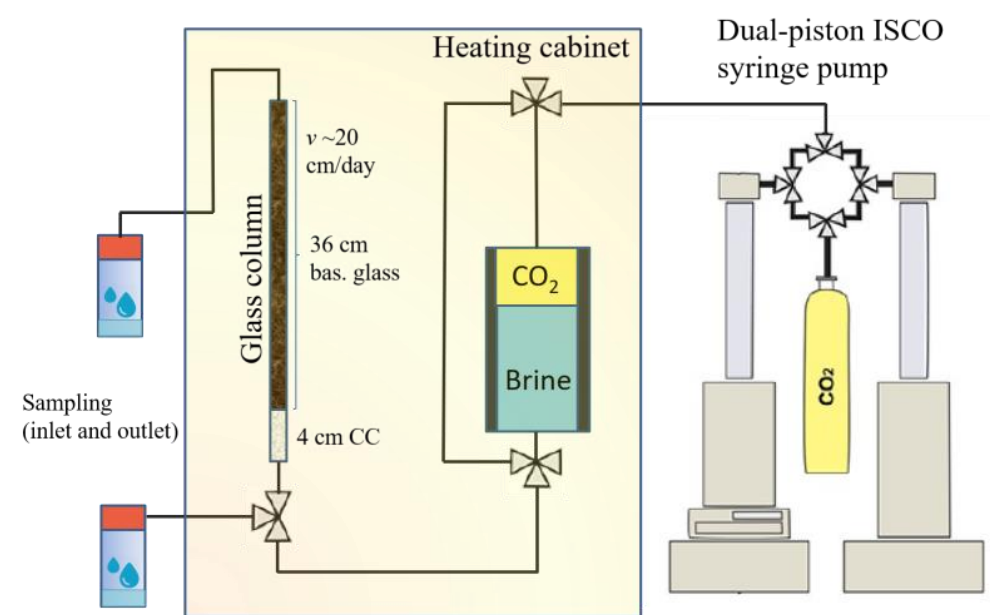

Fig. 1. Experimental setup. Glass column reactor placed inside a heating cabinet to keep a constant temperature of $80^{\circ} \mathrm{C}$. Seawater equilibrated with $\mathrm{CO}_{2}$ flowed at a steady rate of $20 \mathrm{~cm} /$ day ensured by a dual-piston ISCO pump. Sampling was carried out constantly at the outlet, and at some discrete times at the inlet.

\subsubsection{Material}

Basaltic glass of tholeiitic composition from Stapafell, Reykjanes Peninsula, Iceland (see [5] for details), was used as a mineral nucleation substrate for the reactive transport experiments. Basaltic glass offers fast reactivity compared to crystalline materials [6-8], it offers a reasonable chemically homogenous substrate surface, and the dark colour makes the formation of secondary carbonate phases easy to observe.

Seawater used in the column experiments were sampled from the Oslo Fjord and filtered through $0.45 \mu \mathrm{m}$ Millipore $(\mathcal{C}$ filters prior to the experiments. The waters there are 
little affected by freshwater mixing and are compositional close to average North Sea seawater.

\subsubsection{Analytical techniques}

The spatial distribution of secondary precipitates was analysed by visual inspection through the glass wall. $\mathrm{pH}$ of aqueous solutions were analysed immediately after sampling using a standard $\mathrm{pH}$ electrode.

\subsection{Numerical simulations}

PHREEQC v3 [9] with the carbfix.dat thermodynamic database [10] was used to obtain $\mathrm{pH}$ and the saturation states of column fluids with respect to secondary carbonate phases along the flow path. The column was defined according to the experimental setup; $40 \mathrm{~cm}$ long, discretized into 100 cells, and with a flow rate of $20 \mathrm{~cm} /$ day. Cauchy boundary conditions were defined at both inlet and outlet. The inlet seawater solution [11] was equilibrated at $80^{\circ} \mathrm{C}$ to a $\mathrm{CO}_{2}$ partial pressure of $1.0 \mathrm{~atm}$, while the $\mathrm{O}_{2}$ partial pressure was set at $10^{-50} \mathrm{~atm}$. The initial column solution was also seawater but at a low $\mathrm{CO}_{2}$ partial pressure of $10^{-3} \mathrm{~atm}$. Aqueous solutions were defined to be in equilibrium with calcite in the first $4 \mathrm{~cm}$ of the column, and to react kinetically with basalt and with smectites (nontronite and montmorillonite) forming at local equilibrium over the remaining $36 \mathrm{~cm}$. Smectites are known to form during basalt weathering, and were added as a sink to keep aluminium at reasonable and low levels.

The dissolution rate of basalt was modelled as constant along the flow path according to:

$$
R\left(m o l s^{-1} l^{-1}\right)=k S(1-\Omega)
$$

where the rate constant $k$ was approximated from [5] and varied at $1.0 \times 10^{-9-0 \pm 1.0} \mathrm{~mol} / \mathrm{m}^{2} \mathrm{~s}$ at $80^{\circ} \mathrm{C}$ and $\mathrm{pH} 6-7$, and the reactive surface area $S\left(\mathrm{~m}^{2} / \mathrm{l}\right)$, normalized to one litre pore water, was calculated according to:

$$
S\left(m^{2} / l\right)=0.003 / r(1 / \phi-1)
$$

where $\phi$ is porosity estimated to 0.35 and $r$ is the average grain radius $(\mathrm{m})\left(2.5 \times 10^{-4} \mathrm{~m}\right.$ for the basaltic glass). Based on the low inlet silica concentration of $4.3 \mathrm{ppm}$ compared to quartz saturation at $80^{\circ} \mathrm{C}(\sim 34 \mathrm{ppm})$, and precipitation of Al-silicates keeping the aqueous silica fairly low, we approximated the affinity term of the glass to unity, i.e. assuming $\Omega$ $<<1.0$.

\section{Results and discussion}

\subsection{Column experiments}

Pictures taken of the column at four days intervals revealed the formation of white precipitates at seemingly random position along the entire column length, with a larger number forming in the second half of the column (Fig. 2). These white localised precipitates filled the pore space before growth stopped. Their random location and the fact 
that only a few and large crystals formed, suggest overall reaction control by nucleation rather than growth.

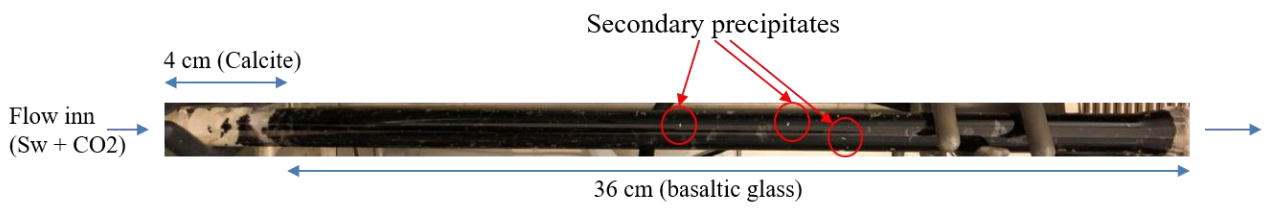

Fig. 2. Column illustrating the patchy mineral precipitates along the flow path. Snapshot of experiment taken after 192 hours.

The $\mathrm{pH}$ of the inlet seawater was measured to be 5.4-5.5 during the 20 days the experiment lasted. After entering the column, the $\mathrm{pH}$ is first buffered to $\sim 6$ in equilibrium with calcite (PHREEQC estimate), before dissolution of basaltic glass further buffers the solution. Measured $\mathrm{pH}$ of outlet solutions were decreasing during the experimental time, from 7.25 at the start to 6.58 at the end (Table 1). The reason for the decrease is not clear yet, but could be caused by reduced basalt dissolution rates or by increased precipitation of secondary carbonate phases with time.

Table 1. $\mathrm{pH}$ measurements of reacted solutions. All inlet $\mathrm{pH}$ were measured at 5.4-5.5. Sample intervals in hours are indicated.

\begin{tabular}{|c|c|c|c|}
\hline Smpl Nr & $\begin{array}{c}\text { Start time } \\
\text { (hours) }\end{array}$ & $\begin{array}{c}\text { End time } \\
\text { (hours) }\end{array}$ & Outlet pH \\
\hline 1 & 0 & 72 & 7.25 \\
\hline 2 & 72 & 240 & 7.10 \\
\hline 3 & 240 & 480 & 6.58 \\
\hline
\end{tabular}

\subsection{Simulated carbonate stabilities}

The 1D reactive transport simulations illustrate that carbonate minerals are stable, and that the reacted solutions get progressively more supersaturated with respect to carbonates as the solutions proceed through the glass column and react with the basalt (Fig. 3). Magnesian carbonates such as dolomite, magnesite, and huntite are all thermodynamically stable, whereas the hydrous forms, such as nesquehonite, are unstable (Fig. 3a). Because of the uncertainty in both reactive surface area and rate constant, three scenarios where rates were varied two orders of magnitude were simulated (Fig. 3b). This results in calcite supersaturations at the end of the column varying from near equilibrium to nearly 1000 times supersaturation. Comparing measured $\mathrm{pH}$ (Table 1) to simulated ones for the three cases $(6.02,6.5$ and 9.5), indicates that the real rate might be comparable to and perhaps slightly higher than the middle case $\left(k=1.0 \times 10^{-9.0} \mathrm{~mol} / \mathrm{m}^{2} \mathrm{~s}\right)$. 
a)

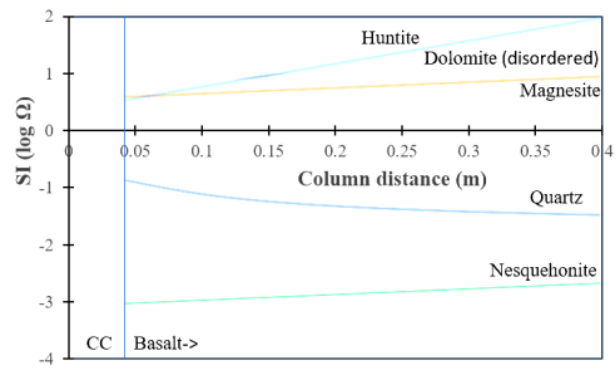

b)

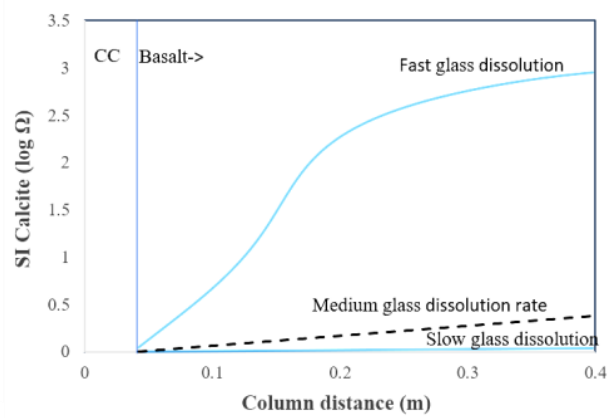

Fig. 3. PHREEQC v3 simulated saturation states of reacted solutions with respect to a) possible solid carbonates using the mid-range basalt dissolution rate $\left(k=1.0 \times 10^{-9.0} \mathrm{~mol} / \mathrm{m}^{2} \mathrm{~s}\right) ;$ and $\left.\mathrm{b}\right)$ calcite at three different basalt dissolution rates; fast $\left(k=1.0 \times 10^{-8.0} \mathrm{~mol} / \mathrm{m}^{2} \mathrm{~s}\right)$, medium $\left(k=1.0 \times 10^{-9.0} \mathrm{~mol} / \mathrm{m}^{2} \mathrm{~s}\right)$, and slow $\left(k=1.0 \times 10^{-10.0} \mathrm{~mol} / \mathrm{m}^{2} \mathrm{~s}\right)$. The snapshots are taken at 1.0 pore volumes of flow.

\section{Implications}

The glass column experiment offers an easy way to visualize the spatial distribution of precipitates. It illustrates that secondary precipitates formed as isolated pockets rather than dispersed in the entire column, as indicated by the estimated carbonate supersaturations. Carbonate precipitation in such a column experiment could be modelled using a TST model, or a model also including nucleation [2]. It would however be impossible to get the nucleation and growth right without using a probabilistic approach to the nucleation step. Local probabilities for nucleation would need to take into account the local interfacial energies, temperature and supersaturations, but also inhibition. This requires both experimental programs, and the development of the probabilistic approach for both porescale and continuum scale applications.

$\mathrm{HH}$ acknowledges a travel grant from the Institute of Geoscience Research at Curtin University, Perth, Western Australia.

\section{References}

1. E.H. Oelkers, S.R. Gislason, J. Matter, Elements, 4 (2008)

2. V.T.H. Pham, P. Lu, P. Aagaard, C. Zhu, H. Hellevang, IJGGC, 5 (2011)

3. V.T.H. Pham, P. Aagaard, H. Hellevang, Geochem. Trans., 13 (2012)

4. N. Pallatt, J. Wilson, B. McHardy, SPE-12798-PA, 36 (1984)

5. S.R. Gislason, E.H. Oelkers, GCA, 67 (2003)

6. S.R. Gislason, H.P. Eugster, GCA, 51 (1987)

7. D.W. Boenisch, S.R. Gislason, E.H. Oelkers, C.V. Putnis, GCA, 68 (2004)

8. D.W.-Boenisch, S.R. Gislason, E.H. Oelkers, GCA, 70 (2006)

9. D.L. Parkhurst, C.A.J. Appelo, USGS Meth., 6 (2013)

10. M. Voigt, C. Marieni, D.E. Clark, S.R. Gislason, E.H. Oelkers, En. Proc., 146 (2018)

11. D.K. Nordstrom, L.N. Plummer, T.M.L. Wigley, et al., CSSS, 93 (1979) 